\title{
Efficiency assessment and output maximization possibilities of European small and medium sized airports
}

\author{
Ester Gutiérrez ${ }^{\S}$ and Sebastián Lozano \\ Department of Industrial Management, University of Seville, \\ Camino de los Descubrimientos s/n 41092-Seville, Spain \\ Artículo publicado en: \\ Research in Transportation Economics (2016), 56, 3-14 \\ http://dx.doi.org/10.1016/j.retrec.2016.07.001
}

\begin{abstract}
The aim of this research is to investigate the operational efficiency and potential output increase scenarios of 21 small and medium sized airports (SMA) located in 10 different European countries. A key feature of the proposed Data Envelopment Analysis (DEA) models is the consideration of two novel inputs related to the number of airlines and scheduled routes operating at each airport, in addition to the more common capital nondiscretionary inputs (runways, boarding gates and apron). These novel inputs are a way of considering the effects of the air transport market on airports' performance and growth prospects. In particular, a model to estimate the growth in passenger numbers, aircraft movements and cargo that can be achieved by an airport through increasing its number of airlines and routes, and assuming an efficient operation, is presented. Also, a multi-objective DEA model is proposed to explore the possible trade-offs in the output Pareto efficient frontier of a given airport. In addition, a second stage fractional regression model specific for explaining DEA efficiency scores is conducted and the results suggest that ownership structure and hub airport status are significant factors for explaining variations in the operational efficiency of European SMA.
\end{abstract}

\footnotetext{
${ }^{\S}$ Corresponding author. Dept. of Industrial Management Escuela Superior de Ingenieros Camino de los Descubrimientos, $\mathrm{s} / \mathrm{n}$ 41092 Sevilla, Spain E-mail: egm@us.es Phone: +34-954486198 Fax: +34-954487329
} 
Keywords: small and medium sizxed airports; Data Envelopment Analysis; output Pareto efficient frontier; augmented weighted Tchebycheff; fractional regression; ownership; hub 


\section{Introduction}

In an increasingly globalizing economy, the importance of air transport as an incomegenerating activity for airport stakeholders, such as municipalities, private agents, public entities, airlines and policy makers, is decisive (Doganis, 1992; Wensveen, 2011). An airport is thus part of an integrated traffic infrastructure that is needed in order to fulfil the framework conditions necessary for a highly developed business location, providing a meaningful economic and social development of the region (Sellner and Nagl, 2010; Button and Yuan, 2013).

The deregulation process in the European Union air transport policy (1990-1998), the Open Skies Agreement (2007/339/EC) and the Single European Sky ATM Research (SESAR) programme have led airlines and airports into a more competitive and dynamic market scenario, forcing them to reduce duplication of services, adapt to rapid technological changes and an uncertain economic environment, dispense with state protectionism and look for economies of scale. In this context, the intra-European air transport sector has a crucial role concerning the economy of Europe by ensuring a robust capacity of its regions for business and leisure. The route system structure of regional carriers and small and medium sized airports (SMA) enables air connectivity and lets smaller regions compete within Europe and with the rest of the world. From a market share analysis, short-haul travel is the largest segment of the world's aviation system. Note, however, that this is true in terms of flight frequency, although, as kindly pointed out by a reviewer, not in terms of Available Seat Kilometres (ASK).

In any case, the recent economic recession has brought new challenges to the European regional industry segment that must be overcome; these are related to efforts to accommodate travellers' demands, alleviating congestion at major airports, changes to state aid rules, more stringent international regulations and emissions taxes on intraEuropean flights, among others. SMA in Europe have their own specificity. Thus, some of the airports sampled in the present study operate low-cost-air carriers in a point-topoint flight routes system while others use a hub-and-spoke architecture. Point-to-point flights can reduce passenger travel time, removing the schedule limitations and operational complexity of connecting flights. They do not allow, however, taking advantage of economies of scale as hub-and-spoke systems do. SMA have also specific 
problems, such as limited capability and limited traffic, and restricted access to resources in order to expand. In this increasingly competitive market, the evaluation of the performance of European SMA can be decisive for airport operators in order to identify 'best practices' airports as well as to assess their own output growth possibilities.

Nowadays SMA compete against one another in terms of air carriers and passengers and in the development of new routes, having considerably more options than in the past. The research that is presented in this paper aims at evaluating the operational efficiency of European SMA by using the well known Data Envelopment Analysis (DEA) methodology and considering two novel inputs related to the regional air carrier business market in addition to the traditional physical inputs of airports. The proposed approach not only rates the efficiency of the airports but also provides a tool to compute alternative, efficient outputs targets. Furthermore, a regression post hoc assessment is conducted in order to test the impact of airport ownership mode and airline hub airport service on the operational performance of European SMA.

The remainder of the paper is set out as follows. In the next section, an overview of the literature on regional airport benchmarking is presented. In Section 3, the proposed approach, which includes several DEA models (for efficiency assessment, extended input-output varying scenarios and output Pareto efficiency frontier exploration based on augmented weighted Tchebycheff multi-objective optimization) and an appropriate fractional regression model for the second-stage DEA analysis, is presented. The results are presented and discussed in Section 4. Finally, Section 5 summarizes and concludes.

\section{Literature review on airports efficiency}

During the 1990s and particularly in the 2000s, considerable interest has been given to the study of the performance of airports in terms of efficiency and productivity change, using Stochastic Frontier Analysis (SFA) and, above all, DEA models. Almost all studies in the airport efficiency literature focus essentially on major international airports (e.g. Gillen and Lall, 1997; Sarkis, 2000; Adler and Berechman, 2001; Lin and Hong, 2006; Ahn and Min, 2014). Table 1 summarizes an extensive literature review on airport DEA efficiency in terms of the inputs and outputs considered - information that 
will be useful for selecting the inputs and outputs to be used in this research. Note that, on the one hand, inputs have been classified within two groups: financial/cost inputs (such as capital costs, labour costs or operating expenses) and physical/operational inputs (such as number of runways, terminal area or number of scheduled flights). On the other hand, outputs have been grouped into three categories: operational outputs (such as aircraft movement, passenger movement and cargo), financial outputs (such as commercial or non-aeronautical revenues) and undesirable outputs (such as flight delays or aircraft noise).

************************Insert Table 1 around here***********************

Some comparative performance analyses across European countries have also been applied using DEA methodology. Adler et al. (2013a) analyzed 43 European airports for the period from 1998 to 2007, using a network DEA model, after a reduction variable stage based on principal component analysis. Suzuki et al. (2014) proposed an extended DEA model based on a distance friction model and fixed factor component which they applied to the 19 most important airports in Europe in 2005.

However, the study of airport efficiency in SMA in the European context has received little attention. Actually, the analysis of SMA efficiency is restricted to a very small number of papers. On the one hand, Merkert and Mangia (2012) studied winter operations in 46 Norwegian regional airports both under a bootstrapped DEA approach and a truncated regression model in the second stage of the analysis. The empirical results revealed that poor technical efficiency is not exclusive to airports with more severe winter conditions. The findings regarding the factors that explain the performance show that geographic location has no significant effect on technical efficiency when a physical input performance analysis is carried out. The opposite effect is found when physical plus financial inputs are considered in the DEA model. Finally, population around the airport and airport size has a significant effect on the physical inputs DEA model. On the other hand, Adler et al. (2013b) focused on the assessment of 85 regional airports across seven European countries using a variable returns to scale approach based on an additive DEA model. Their research found that substantial cost savings can be obtained. In a second stage, ordinary and truncated 
regression analyses revealed that small regional airports behaved differently from large hub airports.

\section{Dataset and methodology used}

This section presents the data considered in this research and outlines the methodology used in this study.

\subsection{Dataset}

The data for this study correspond to a sample of 21 European SMA observed in 2013, categorized as ACI Group 4 airports (Airports Council International Europe, 2015), welcoming fewer than five million passengers per year, and therefore belonging to the 4th and 5th tiers, as per Burghouwt's (2007) classification. Most of these airports are small regional airports, with a route network to other countries and other domestic destinations operating as point-to-point air carriers with route switching power. Most SMA operators have adopted the corporate business model as a management perspective. Table 2 provides the characteristics of this sample of SMA, showing large variations among the sample airports in terms of infrastructure and operational settings. For instance, the aircraft movements range from 3,000 operations for Rijeka (Croatia) to 1.2 million operations for London City (U.K.). The average number of travellers per aircraft movement was 97.33 at Salzburg airport, but only 2.98 travellers per aircraft movement at Antwerp airport. The sample includes airports that do not have cargo, such as Bern Belp, Groningen, London City, Norwich, Southampton and Waterford. Some airports offer mostly seasonal destinations, such as, Innsbruck, Nantes, Norwich, Pula, Rijeka, Salzburg, Shannon, whereas others offer mostly year-round destinations, such as Antwerp, Budapest, London City and Waterford. Some airports provide services mostly to long-haul aircraft, whereas others serve mainly short-haul aircraft, such as Antwerp, Bern Belp, London City and Southampton. Note that Manston airport (U.K.) has not been included in the sample as it has recently suspended its operations because it ceased to be a commercially viable option for current and potential passenger and freight operators.

*************************Insert Table 2 around here************************ 
The proposed approach uses as inputs three variables that, according to the literature review, are commonly used and which refer to the runway size (RUNAREA), boarding gates (BOARDG) and apron stands (APRON). In addition, two novel inputs have been considered, namely the number of scheduled routes (SCHROUT) and the number of airlines (AIRLINES) that operate in each airport. The first group of inputs corresponds to the infrastructure/facilities of the airport while the second group of inputs represents managerial inputs and refers to the ability of managers to attract and retain air transport operators. All the inputs are fixed, a.k.a. non-discretionary, i.e. the proposed DEA model for efficiency assessment does not try to reduce those inputs because that is not reasonable. As regards the number of airlines and the number of scheduled routes, since they are in principle "fixed", these two non-discretionary variables can alternatively be considered as inputs or as outputs. We have opted for considering them as inputs because, as described below, we want to carry out the estimation of the output increase that might be achieved if those non-discretionary inputs were in the end increased through effective airport management intervention. Thus, the DEA model proposed for that purpose considers those two inputs non-discretionary (in the sense of non considering reducing them as a possibility) but assumes that they have been increased with respect to their initial, observed value. Hitherto, there have been no studies that include airlines routes and the number of carriers that operate in airports.

With regard to outputs, the three considered here are: aircraft movements (MOV), passenger throughput (PAX) and cargo handled (CARGO). These are the three most important and more frequently used operational outputs (see Table 1). Data for the inputs and outputs variables come from several sources, including the European Regions Airline Association, Annual Reports of the sample of airports, Wikipedia, and the authors' direct contact with the airports concerned. Note, finally, that other inputs, such as labour and other operating costs, could also have been considered, provided that the corresponding data were available, which is not the case in the study reported in this paper. 


\subsection{Proposed DEA models}

The proposed DEA models consider output orientation and Variable Returns to Scale (VRS). In the first place, a basic radial technical efficiency assessment is carried out using a conventional BCC-O DEA model (Banker et al., 1984). Let

Data

i index on inputs

$\mathrm{k} \quad$ index on outputs

$\mathrm{j} \quad$ index on airports

$\mathrm{n} \quad$ number of airports being benchmarked

$\mathrm{x}_{\mathrm{ij}} \quad$ amount of input $\mathrm{i}$ corresponding to airport $\mathrm{j}$

$\mathrm{y}_{\mathrm{kj}} \quad$ amount of output $\mathrm{k}$ corresponding to airport $\mathrm{j}$

$0 \quad$ index of the specific airport being assessed

$\varepsilon \quad$ a non-Archimedean infinitesimal

Variables

Eff $_{0} \quad$ efficiency score of airport 0

$\gamma \quad$ potential radial output expansion of airport 0

$\mathrm{s}_{\mathrm{k}} \quad$ slack of output $\mathrm{k}$ (additional to the radial output expansion) for airport 0

$\lambda_{1}, \lambda_{2}, \ldots, \lambda_{\mathrm{n}}$ intensity variables used to compute efficient projection of airport 0

\section{$\underline{\text { Technical efficiency assessment DEA model }}$}

$$
\operatorname{Eff}_{0}{ }^{-1}=\operatorname{Max} \quad \gamma+\varepsilon \cdot \sum_{\mathrm{k}} \mathrm{s}_{\mathrm{k}}
$$

s.t.

$\sum_{\mathrm{j}} \lambda_{\mathrm{j}} \mathrm{x}_{\mathrm{ij}} \leq \mathrm{x}_{\mathrm{i} 0} \quad \forall \mathrm{i}$

$\sum_{\mathrm{j}} \lambda_{\mathrm{j}} \mathrm{y}_{\mathrm{kj}}=\gamma \mathrm{y}_{\mathrm{k} 0}+\mathrm{s}_{\mathrm{k}} \quad \forall \mathrm{k}$

$\sum_{\mathrm{j}} \lambda_{\mathrm{j}}=1$

$\lambda_{\mathrm{j}} \geq 0 \quad \forall \mathrm{j} \quad \mathrm{s}_{\mathrm{k}} \geq 0 \quad \forall \mathrm{k} \quad \gamma$ free 
Solving the above model a second time without the convexity constraint (4) allows determining the global efficiency $\mathrm{Eff}_{0}^{\mathrm{CRS}}$, i.e. the efficiency under Constant Returns to Scale (CRS). The scale efficiency of the airports is thus

$$
\mathrm{Eff}_{0}^{\text {scale }}=\frac{\text { Eff }_{0}^{\mathrm{CRS}}}{\mathrm{Eff}_{0}}
$$

It is also possible to estimate the local Returns To Scale (RTS) of the different outputs. A simple way is by solving the above model again but substituting the convexity constraint (4) by this relaxed version, which corresponds to assuming Non-Increasing Returns to Scale (NIRS).

$$
\sum_{j} \lambda_{j} \leq 1
$$

Let us call the optimal solution of this relaxed model Eff $_{0}^{\text {NIRS }}$. The local RTS of airport 0 can then be classified as CRS, Increasing Returns to Scale (IRS) or Decreasing Returns to Scale (DRS) as per

$$
\begin{aligned}
& \mathrm{CRS} \text { if } \mathrm{Eff}_{0}^{\mathrm{CRS}}=\mathrm{Eff}_{0}^{\mathrm{NIRS}}=\mathrm{Eff}_{0} \\
& \text { IRS if } \mathrm{Eff}_{0}^{\mathrm{CRS}}=\mathrm{Eff}_{0}^{\mathrm{NIRS}}<\mathrm{Eff}_{0}
\end{aligned}
$$

$$
\mathrm{DRS} \text { if } \mathrm{Eff}_{0}^{\mathrm{CRS}}<\mathrm{Eff}_{0}^{\mathrm{NIRS}}=\mathrm{Eff}_{0}
$$

The above efficiency assessment also allows the computing of output targets for each airport; this corresponds to determining the output increases that can be achieved with the current number of scheduled routes and number of airlines. This can be interpreted as a measure of operational efficiency as well as a measure of the extent to which the available capacity is used.

Moreover, DEA analysis also allows the estimation of the output increases that could be achieved in case of an increase in the amounts of inputs available. Although all the inputs are considered non-discretionary in the sense that its reduction is not deemed desirable, for some managerial inputs (namely, number of airlines and scheduled routes), let us call this subset $\mathrm{I}^{\mathrm{M}}$, it may be possible, through effective management intervention, to increase them. In particular, the purpose of the model presented below is to compute the output increases associated with a hypothetical increase in these two 
managerial inputs. Let $\alpha=\alpha_{i}$, a vector whose $\mathrm{i}$-th component $\alpha_{\mathrm{i}}$ is the increase in the amount of input $i \in \mathrm{I}^{\mathrm{M}}$ available to airport 0 . Then the corresponding radial output increase can be computed using the following:

$\underline{\text { Output-increase estimation DEA model }}$

$\gamma_{0} \quad \alpha=\operatorname{Max} \quad \gamma+\varepsilon \cdot \sum_{\mathrm{k}} \mathrm{s}_{\mathrm{k}}$

s.t.

$\sum_{\mathrm{j}} \lambda_{\mathrm{j}} \mathrm{x}_{\mathrm{ij}} \leq \mathrm{x}_{\mathrm{i} 0} \quad \forall \mathrm{i} \notin \mathrm{I}^{\mathrm{M}}$

$\sum_{\mathrm{j}} \lambda_{\mathrm{j}} \mathrm{x}_{\mathrm{ij}} \leq \mathrm{x}_{\mathrm{i} 0}+\alpha_{\mathrm{i}} \quad \forall \mathrm{i} \in \mathrm{I}^{\mathrm{M}}$

$\sum_{\mathrm{j}} \lambda_{\mathrm{j}} \mathrm{y}_{\mathrm{kj}}=\gamma \mathrm{y}_{\mathrm{k} 0}+\mathrm{s}_{\mathrm{k}} \quad \forall \mathrm{k}$

$\sum_{\mathrm{j}} \lambda_{\mathrm{j}}=1$

$\lambda_{\mathrm{j}} \geq 0 \quad \forall \mathrm{j} \quad \mathrm{s}_{\mathrm{k}} \geq 0 \quad \forall \mathrm{k} \quad \gamma$ free

Note that the conventional efficiency assessment corresponds to solving the above model for $\alpha=0,0$, i.e. $\operatorname{Eff}_{0}{ }^{-1}=\gamma_{0}(0,0)$. The above model, however, allows computing the potential output increases that can be achieved if the managers of airport 0 are able to increase the number of scheduled routes and the number airlines by the amounts given by the respective components of vector $\alpha$. Varying $\alpha$, the surface $\gamma_{0} \alpha$ can be computed and plotted for each airport 0 . This will be illustrated in Section 4.1.

An additional DEA analysis that can be done is an exploration of the different Pareto efficient output targets that can be achieved by a given airport 0 assuming its current inputs. The idea behind this multi-objective DEA analysis is different from that of both model (1)-(5) and model (8)-(13), which assume a radial expansion of the outputs, which means maintaining the observed output mix. On the other hand, the managers of 
airport 0 may be interested in exploring other efficient output targets which means calculating the corresponding output Pareto efficient frontier. Something similar, but with an input orientation, was carried out in Lozano and Gutiérrez (2011c) in a multiobjective study of fleet, fuel and operating cost efficiency of European airlines. However, while in Lozano and Gutiérrez (2011c) all extreme Pareto efficient operation points were computed using the vintage ADBASE Multi-objective Linear Programming software (Steuer, 2006), in this application we will, instead, sample the output Pareto efficient frontier using an augmented weighted Tchebycheff DEA approach which is formulated below. Alternatively, an interactive weighted Tchebycheff approach, such as the one proposed in Steuer and Choo (1983), can be used. In any case, it seems reasonable to limit the exploration of the output Pareto efficient frontier to the region that dominates the current operation point since managers surely want to increase all outputs. To that end let

\section{Data}

$\mathrm{y}_{\mathrm{k} 0}^{\max }$ maximum amount of output $\mathrm{k}$ that airport 0 can achieve with its current inputs (ideal point of airport 0)

$\mathrm{w}_{\mathrm{k}} \quad \mathrm{k}$-th component of weight vector used for projection from ideal point of airport 0

\section{Variables}

$\mu_{0} \quad$ Tchebycheff distance of target operation point of airport 0 to its ideal point $\hat{\mathrm{y}}_{\mathrm{k} 0} \quad$ target value for output $\mathrm{k}$ of airport 0

The idea is to solve the model below using different weight vectors so that different efficient output targets that dominate the current operation point and do not consume more than the current inputs can be calculated.

\section{$\underline{\text { Augmented weighted Tchebycheff DEA model }}$}

$\operatorname{Min} \mu_{0}+\varepsilon \cdot \sum_{\mathrm{k}} \mathrm{y}_{\mathrm{k} 0}^{\max }-\hat{\mathrm{y}}_{\mathrm{k}}$

s.t.

$$
\sum_{\mathrm{j}} \lambda_{\mathrm{j}} \mathrm{x}_{\mathrm{ij}} \leq \mathrm{x}_{\mathrm{i} 0} \quad \forall \mathrm{i}
$$




$$
\begin{aligned}
& \sum_{\mathrm{j}} \lambda_{\mathrm{j}} \mathrm{y}_{\mathrm{kj}}=\hat{\mathrm{y}}_{\mathrm{k} 0} \geq \mathrm{y}_{\mathrm{k} 0} \quad \forall \mathrm{k} \\
& \mu_{0} \geq \mathrm{w}_{\mathrm{k}} \cdot \mathrm{y}_{\mathrm{k} 0}^{\max }-\hat{\mathrm{y}}_{\mathrm{k}} \quad \forall \mathrm{k} \\
& \sum_{\mathrm{j}} \lambda_{\mathrm{j}}=1 \\
& \lambda_{\mathrm{j}} \geq 0 \quad \forall \mathrm{j} \quad \mu_{0} \text { free }
\end{aligned}
$$

Given the current inputs of airport 0 , this augmented weighted Tchebycheff DEA model looks for an operation point, computed using the assumed VRS DEA technology, whose outputs dominate the current outputs of airport 0 and are as close as possible, weighted by vector $\overline{\mathrm{w}}$, from the maximum ideal output levels of airport 0 .

\subsection{Second stage: Fractional regression models}

In order to explore the influence of exogenous factors in the airport's efficiency, a second stage regression analysis can be carried out. The linear and Tobit models frequently used in second stage DEA efficiency analyses are, however, not suitable, in general, for the description of DEA scores data (Maddala, 1991; Papke and Wooldridge, 1996; Ruggiero, 1998; Hoff, 2007; Simar and Wilson, 2007; McDonald, 2009). Ramalho et al. (2010) and (2011) provide a proper statistical basis for second stage DEA efficiency analyses, proposing generalizations of fractional models without boundary observations and flexible distributional assumptions. This type of regression analysis does not seem to have been applied yet to explain the results of transportation efficiency studies.

Applying the Ramalho et al. (2010) approach, the proportional regression model, in terms of the conditional mean model for the proportional variable, Eff ${ }^{-1}, 0 \leq$ Eff $^{-1} \leq 1$, is defined by:

$$
E \operatorname{Eff}^{-1} \mid x=H(x v)
$$

where $x$ is a vector of $k$-covariates, $H(\cdot)$ is a known nonlinear function, $0 \leq H(\cdot) \leq 1$ and $v$ is the vector of the parameters. Although nonlinear conditional mean specifications can adopt a variety of functional forms (Papke and Wooldridge, 1996; Ramalho et al. 
2010), the nonlinear logit and complementary cloglog functions (21) and (22), respectively, are selected as link functions:

$$
\begin{aligned}
& E \operatorname{Eff}^{-1} \mid x=\frac{e^{x V}}{1+e^{x V}} \\
& E \operatorname{Eff}^{-1} \mid x=1-\exp [-\exp x v]
\end{aligned}
$$

In our case $x$ is just a bidimensional vector of covariates (corresponding to ownership type and hub status, see Section 4.2) and $v$ is the vector of regression parameters. The empirical analysis is applied to specifications justifiable by the RESET test (misspecification of the first order). The corresponding frm add-on package for the statistical software R (Ramalho, 2015) has been used for computing the estimation, specification analysis and calculation of partial effects of fractional regression models.

\section{Empirical results}

This section presents the results obtained using the methodology described in the previous section. This includes, in Section 4.1., an output-oriented technical efficiency assessment of the SMA in the sample, an estimation of the potential output increase associated with a hypothetical increase in the number of airlines and scheduled routes in a given airport and, finally, the computation of a discretization of the output Pareto front associated to the input vector of each airport. Then, in Section 4.2., a second stage regression analysis of the output-oriented technical efficiency scores obtained is carried out using the ownership type (private/public) and the hub/non-hub type as independent variables.

\subsection{DEA analysis results}

As regards the DEA analysis, Table 3 shows the output-oriented efficiency assessment. Both the radial expansion score $\gamma$ and the outputs slacks $\mathrm{s}_{\mathrm{k}}$ corresponding to the solution of model (1)-(5) for each airport, are shown. The corresponding normalized efficiency score Eff $_{0}$, as well as those obtained assuming CRS and NIRS, are shown. From these scores the scale efficiency and local RTS of each airport are obtained. Note that most of the airports are deemed to be technically efficient. That is not surprising, given that the number of airports evaluated is not large in relation to the number of inputs and outputs considered. The discriminant power of DEA, of course, increases as the number of units being assessed increases. Note, however, that not all technically 
efficient airports are scale efficient. There are three that are not CRS efficient, i.e. they do not operate at their Most Productive Scale Size (Banker, 1984). Thus, two of these three technically efficient airports (namely A20 and A21) exhibit IRS while the third one (namely A12) exhibits DRS. All the technically inefficient airports exhibit IRS. Finally, note that the two most technically inefficient airports are A14 and A15, which, to be become efficient, need to more than double their current outputs. The rest of the technically inefficient airports do not have such low efficiency scores.

************************** Insert Table 3 around here $* * * * * * * * * * * * * * * * * * * * * * *$

Table 4 shows the benchmarks for each inefficient airport. Airports A10, A5, A3 and A18 are those that appear more frequently as benchmarks, which means their input and output bundles are the most representative efficient operating points. There are a number of airports (namely A1, A2, A4, A7, A9, A12 and A13) which, although efficient, do not appear as a benchmark of any of the inefficient airports. This means that these airports' operating points are somewhat specific, i.e. their input and output bundles are particular.

************************** Insert Table 4 around here $* * * * * * * * * * * * * * * * * * * * * * *$

We have also carried out the estimation, for each airport, of the potential output increases $\gamma_{0} \alpha_{\text {SCHROUT }}, \alpha_{\text {AIRLINES }}$ that could be achieved, provided the managers increase the current number of scheduled routes and airlines by $\alpha_{\text {SCHROUT }}$ and $\alpha_{\text {AIRLINES }}$ respectively. We considered vales $\alpha_{\text {SCHROUT }}=0,2,4, \ldots, 20$ and $\alpha_{\text {AIRLINES }}=0,1,2, \ldots, 10$. Note that $\alpha_{\text {SCHROUT }}=\alpha_{\text {AIRLINES }}=0$ corresponds to the current situation and therefore provides the same output increases given by the efficiency assessment commented on above. Figure 1 shows these $\gamma_{0} \alpha_{\text {SCHROUT }}, \alpha_{\text {AIRLINES }}$ values. Note that for some airports, no increase in outputs seems to be achievable by increasing the current number of scheduled routes and airlines. That indicates that those two inputs are not the ones that are constraining the outputs, which is not the case for other airports. Actually it can be said that the situation is different for each airport. One of the advantages of the proposed DEA model (8)-(13) 
is that it allows studying the case of each airport individually. Thus, for example, for some airports, such as A8, A16 or A17, it seems that increasing the number of airlines would not lead to increased outputs, and increasing the number of scheduled routes would initially allow increased outputs but the larger increase would have no effect. For other airports, for example, A6, the increase in outputs is feasible for the whole range of $\alpha_{\text {SCHROUT }}$ values considered. For other airports, for example, A19, it is the opposite; the number of scheduled routes would not be as beneficial for increasing the outputs as increasing the number of airlines would be. Finally, for some airports, such as A18, the increase of both the number of scheduled routes and of airlines would allow them to increase their target outputs.

************************ Insert Figure 1 around here $* * * * * * * * * * * * * * * * * * * * * * *$

Another interesting analysis that has been carried out is the exploration of the output Pareto efficient frontier as per model (14)-(19). Figure 2 shows the results for one of the airports, namely airport A6 (Cardiff). To sample this output Pareto front a large number of weight vectors $\overline{\mathrm{w}}=\mathrm{w}_{\mathrm{MOV}}, \mathrm{w}_{\mathrm{PAX}}, \mathrm{w}_{\mathrm{CARGO}}$ are used. For a grid size of 0.05 this gives close to 20,000 points weight vectors. For each weight vector, using model (14)(19) a Pareto output efficient operating point is obtained. Note that two weight combinations may produce the same Pareto efficient point. Note also that, in order to visualize the whole Pareto efficient front, the operating points plotted in Figure 2 correspond to a relaxed version of constraint (16) so that the target operating point does not necessarily have to be larger than the observed value for A6. Thus, of all the Pareto efficient points shown in Figure 2, only a fraction (343 points in the case of DMU A6) have output levels that dominate the current output values of that airport.

Since each Pareto output efficient point involves three output components and in order to be able to visualize the Pareto front, each output dimension is plotted separately. This is equivalent to the typical parallel coordinates scheme to plot multidimensional Pareto efficient points. Thus, for each weight vector $\overline{\mathrm{w}}=\mathrm{w}_{\mathrm{MOV}}, \mathrm{w}_{\mathrm{PAX}}, \mathrm{w}_{\mathrm{CARGO}}$ the corresponding output value along each of the three dimensions is shown in each of the three surfaces shown. Since it is difficult to visualize some 3D surfaces in the plane, for each surface two different perspectives are shown. Note also that the weight vectors 
$\overline{\mathrm{w}}=\mathrm{w}_{\text {MOV }}, \mathrm{w}_{\mathrm{PAX}}, \mathrm{w}_{\mathrm{CARGO}}$ are normalized which means that only two components ( $\mathrm{w}_{\text {MOV }}$ and $\mathrm{w}_{\text {PAX }}$ in this case) are necessary to represent each point.

**************************) Insert Figure 2 around here $* * * * * * * * * * * * * * * * * * * * * * *$

As regards the MOV output it can be seen that the surface is almost flat with values in the range of 46,000-50,000 aircraft movements (which is two times the current number of operations for A6, i.e. 24,879). For very low values of $\mathrm{w}_{\mathrm{PAX}}$, however, the Pareto front involves a much lower number of operations (as low as 11,000 passengers) although it increases quickly, reaching the flat region and even surpassing it, as $\mathrm{w}_{\mathrm{MOV}}$ increases. This is not surprising since increasing the weight given to the MOV output should increase the target value for that output.

As regards the second output (PAX) there is again an extensive flat region also at a maximum value of $1,190,000$ passengers, slightly above the observed value for A6 (1,072,000 passengers), Again, very low values of $\mathrm{w}_{\mathrm{PAX}}$, this output is lower but increases as $\mathrm{w}_{\text {MOV }}$ increases. For those weight combinations, we have seen above that MOV also increases. That is consistent with the positive correlation between aircraft traffic movement and passenger throughput. There seems to be, however, for these low values of $\mathrm{w}_{\mathrm{PAX}}$ a small decrease of PAX (to 1,100,000 passengers aprox.) for large values of $\mathrm{w}_{\mathrm{MOV}}$.

Finally, the variable CARGO has an extensive flat region, with very low values (at around 950 tonnes), although the variable increases, same as the other two variables, for small values of $w_{\text {PAX }}$. The increase is specially intense for low values of both $\mathrm{w}_{\text {PAX }}$ and $\mathrm{w}_{\mathrm{MOV}}$, which, not by chance, correspond to large values of $\mathrm{w}_{\mathrm{CARGO}}$.

Note that, although the renderings shown in Figure 2 can give an idea of the feasible trade-offs among the output variables across the Pareto efficient frontier, the numerical results provided by model (14)-(19), which can also be solved within an interactive multi-objective optimization approach, allow for amore precise (i.e. quantitative) estimation of the different output target levels that can be achieved. Finally, note that 
Figure 2 corresponds to just one of the inefficient airports. For other airports, the number of efficient operating points dominating the current output levels is larger and for others is smaller. Actually, in the case of the efficient airports there are no other efficient operating points with larger output levels. Again, an interesting feature of the proposed DEA approach is that it allows a case by case analysis, tailored to the situation and preferences of each airport.

\subsection{Regression analysis}

In order to try to better understand the airports' efficiency scores obtained, a regression analysis has been performed using the reciprocal of the technical efficiency scores as a dependent variable. The literature on second stage regression in airports' performance analysis provides an extensive number and variety of independent contextual variables, allowing the formulation of a large number of different regression models.

Despite the diversity of airport ownership regimes, the airports considered in our empirical study operate under two poles: public-owned (government/municipalities) airports and private-owned airports. Likewise, airports have been classified as hubs or non-hubs based on the information provided by the own airlines. Thus, an airport is considered a hub if there is an airline that uses it as a hub. Therefore, the contextual variables considered as regressors are two zero-one dummy variables: OWNERSHIP (if public ownership=0, private ownership=1) and HUB (if the airport does not operate as an airline hub=0; if it operates as an airline hub=1). The base cases are, therefore, the airports that are privately-owned and used as hubs, e.g. Bern Belp, Budapest, Nantes and Southampton. The models' specifications assume that the relationship between ownership structure and hub airport status is additive.

For the Tobit censored regression model, the efficiency scores are left-right censored at zero and one, respectively. Table 5 reports the regression results obtained for three alternative models considered: two conventional models (linear model and censoredTobit model) and two novel fractional regression models, (1) and (2), more appropriate for DEA efficiency scores. The results show that, although not all coefficients are statistically significant, the directions of the estimated coefficients coincide for all the models considered. Note, in particular, the differences between the linear and Tobit 
models on one side, and fractional models on the other, as regards the HUB factor, which is significant at the 0.01 level in the logit and cloglog models but not in the linear and Tobit models.

For each model, a comparable coefficient of determination, $\mathrm{R}^{2}$, is calculated as a goodness of fit measure. Note that $\mathrm{R}^{2}$ values are similar across the models. It is noteworthy that the $\mathrm{R}^{2}$ values in fractional models are identical and $15 \%$ higher than in the linear model and $25 \%$ higher than in the McFadden's pseudo- $\mathrm{R}^{2}$ in the Tobit model. Additionally, the RESET test confirms the correct functional form specification for linear and fractional models. In order to explain the probability of an airport operating on the efficiency frontier, the cloglog functional form is appropriate due to the asymmetric character of the efficiency scores distribution $(14$, i.e. $66 \%$, of the airports operated in the efficient frontier).

**************************Insert Table 5 around here*************************

Table 6 reports the estimates of partial average estimates for the logit and cloglog models. The partial effects estimated under the logit specification are not very different from those estimated under the cloglog specification. Both models indicate that the effect of ownership on SMA efficiency is about 14\% and 12\% larger, in logit and cloglog, respectively, for public than for private SMA. This result was contrary to our expectations; however, similar results are found in the study of Curi et al. (2010) on the efficiency of Italian airports and in the research conducted by Ha et al. (2013) on the performance evaluation of Northeast Asian airports. These results provide some evidence that privatization is not a key driver for higher utilization of the available airport infrastructure and higher productivity at the regional level. The explanation may be related to the running of SMA under the close supervision of state/local authorities due to airports' strategic contribution to regional development. In this respect, in some SMA, subsidization of the airport infrastructure might be a decisive but controversial issue, if they are compared with major airports.

Furthermore, both fractional models coincide in that the effect of hub status on efficiency is larger, about $19 \%$ and $15 \%$ in logit and cloglog, respectively, for SMA offering airline hub services than those not offering airline hub services. The significant 
differentiation in efficiencies between hub and non-hub SMA is supported by the coincident findings of Gillen and Lall (1997) and Sarkis (2000) for U.S. airports, Fung et al. (2008) in their evaluation of Chinese airports, and Tsui et al. (2014) in the AsiaPacific airports. This result may be due to the economies of scale operating in airport hubs also at the regional level.

************************Insert Table 6 around here***********************

\section{Conclusions}

European SMA provide a vital complementary and supporting function to the consolidating European network of airline operators. In addition, performance evaluation is one of the pillars in the pursuance of the Single European Sky framework, unifying objectives for governments, managers and shareholders. In that context, this paper aims to provide a contribution to decision making and planning for SMA efficiency assessment and improvement. In particular, the paper makes several contributions to airport performance literature. Firstly, we estimate European SMA technical efficiency with the inclusion of two novel managerial inputs (number of scheduled routes and number of airlines) motivated by the recent operational flexibility for destination switching from the air carriers' side. A second DEA model has been proposed to estimate the growth potential of each airport as a function of these managerial inputs. Thirdly, an approach to compute the output Pareto efficient frontier of a given airport, based on the augmented weighted Tchebycheff method, is proposed. Finally, we provide empirical evidence, based on a fractional regression analysis that uses a specific data-generating process for DEA results, on the impact of hub status and ownership on the efficiency of SMA in the European context.

The proposed VRS, output-oriented DEA models allow the identification of a number of inefficient airports, for each of which its output targets have been computed. For both efficient and inefficient airports, the increase in aircraft movements, passenger traffic and cargo if the number of airlines and scheduled air routes is increased, and assuming efficient operation, has been estimated. It has been observed that the growth profile is different and specific for each airport, depending on its current level of utilization of its physical assets. Finally, when used for studying the case of each specifically inefficient 
airport, the proposed multi-objective DEA approach allows managers to explore tradeoffs between the outputs of alternative efficient operating points and thus develop appropriate strategic plans to achieve the selected target output levels.

The second-stage DEA analysis also reveals that the operational performance of European SMA is significantly related to the ownership regime and hub airline airport status. With respect to ownership, SMA that are publicly owned have higher operational efficiencies than those that are privately owned. With respect to hub status, hub SMA have higher operational efficiencies than non-hub SMA.

Finally, mention should be made of the drawbacks and limitations of the study. An obvious one is the small size of the dataset used. Data availability issues should be addressed at the sector level in which case the results of this study could be confirmed with a larger sample of airports. Another limitation is the fact that this study has employed cross-sectional data. Further research is necessary to gain a deeper understanding of the progress adaptation of the airports to the new European air transport framework. In this sense, one possible research avenue could be to apply the Malmquist productivity index method using a resampling approach (Simar and Wilson, 2007). Also, it would be interesting to differentiate between airports with traditional operators versus low cost carriers, airports contracting versus outsourcing activities and different management arrangements in order to analyze the impact that internationalization operations have on airports. The latter would allow the customization of airports' performance and identify opportunities to improve the current operations. In addition, this performance research has focused on capital and operational inputs; a potential extension of this research would be to consider also variables related to revenues from aviation/non-aviation activities, labour costs and other operating expenses and externalities of airports operations (e.g. air pollution or noise).

\section{Acknowledgements}

This research was carried out with the financial support of the Spanish Ministry of Science grant DPI2013-41469-P and the European Regional Development Fund (ERDF). We would also like to thank Holly Butler, of the European Regions Airline Association, and the participating airports for their assistance in providing the data for 
this study. Finally, the authors are also thankful to the reviewers for their helpful comments and suggestions.

\section{References}

Adler N., Berechman J. (2001) Measuring airport quality from the airlines' viewpoint: An application of data envelopment analysis, Transport Policy, 8, 171-81

Adler, N., Liebert, V., Yazhemsky, E. (2013a) Benchmarking airports from a managerial perspective, Omega, 41, 442-458

Adler, N., Ülku, T., Yazhemsky, E. (2013b) Small regional airport sustainability: lessons from benchmarking, Journal of Air Transport Management, 33, 22-31

Ahn, Y-H., Min, H. (2014) Evaluating the multi-period operating efficiency of international airports using data envelopment analysis and the Malmquist productivity index, Journal of Air Transport Management, 39, 14-22

Airports Council International Europe (2015) Airport Traffic Report. Air Council International, Geneva. (https://www.aci-europe.org/ Last accessed March 15 2015)

Assaf, A.G., Gillen, D. (2012) Measuring the joint impact of governance form and economic regulation on airport efficiency, European Journal of Operational, 220, 187198

Banker R, Charnes A., Cooper W.W. (1984) Some models for estimating technical and scale inefficiencies in data envelopment analysis, Management Science, 30, 1078-92

Banker, R.D. (1984) Estimating most productive scale size using data envelopment analysis, European Journal of Operational Research, 17, 35-44

Barros, C.P., Dieke, P.U.C. (2007) Performance evaluation of Italian airports: A data envelopment analysis, Journal of Air Transport Management, 13, 184-191

Barros, C.P., Dieke, P.U.C. (2008) Measuring the economic efficiency of airports: A Simar-Wilson methodology analysis, Transportation Research Part E, 44, 1039-1051

Bazargan, M., Vasigh, B. (2003) Size versus Efficiency: a Case Study of US Commercial Airports, Journal of Air Transport Management, 9, 187-193 
Burghouwt, G. (2007) Airline Network Development in Europe and its Implications for Airport, Ashgate Pub. Co.

Button, K., Yuan, J. (2013) Airfreight transport and economic development: an examination of causality, Urban Studies, 50, 329-340

Chow, C.K.W., Fung, M.K.Y. (2012) Estimating indices of airport productivity in Greater China, Journal of Air Transport Management, 24, 12-17

Curi, C., Gitto, S., Mancuso, P. (2010) The Italian airport industry in transition: a performance analysis, Journal of Air Transport Management, 16, 218-221

De Nicola, A., Gitto, S., Mancuso, P. (2013) Airport quality and productivity changes: A Malmquist index decomposition assessment. Transportation Research Part E: Logistics and Transportation Review, 58, 67-75.

Doganis, R. 1992. The Airport Business, Routledge, London.

Fernandes, E., Pacheco, R.R. (2002) Efficient use of airport capacity, Transportation Research Part A: Policy and Practice, 36, 225-238

Fung, M-K-Y, Wan, K-K-H, Hui Y-V, Law, J-S. (2008) Productivity changes in Chinese airports 1995-2004, Transportation Research Part E, 44, 521-542

Gillen D., Lall, A. (1997) Developing Measures of Airport Productivity and Performance: An Application of Data Envelopment Analysis, Transportation Research Part E: Logistics and Transportation Review, 3, 261-273.

Ha, H-K., Wan, Y., Yoshida, Y. Zhang, A. (2013) Airline market structure and airport efficiency: Evidence from major Northeast Asian airports, Journal of Air Transport Management, 33, 32-42

Hoff, A. (2007) Second stage DEA: comparison of approaches for modelling the DEA score, European Journal of Operational Research, 181, 425-435

Li, S.L. (2014) The cost allocation approach of airport service activities, Journal of Air Transport Management, 38, 48-53 
Lin, L.C., Hong, C.H. (2006) Operational performance evaluation of international major airports: An application of data envelopment analysis, Journal of Air Transport Management, 12, 342-351

Lozano, S., Gutiérrez, E. (2011a) Efficiency Analysis and Target Setting of Spanish Airports, Networks and Spatial Economics, 11,139-157

Lozano, S., Gutiérrez, E. (2011b) Slacks-Based Measure of Efficiency of Airports with Airplanes Delays As Undesirable Outputs, Computers \& Operations Research, 38, 131139

Lozano, S., Gutiérrez, E. (2011c) A Multiobjective Approach to Fleet, Fuel and Operating Cost Efficiency of European Airlines. Computers \& Industrial Engineering, $61,473-481$

Lozano, S., Gutiérrez, E., Moreno, P. (2013) Network DEA approach to airports performance assessment considering undesirable outputs, Applied Mathematical Modeling, 37, 1665-1676

Maddala, G.S. (1991) A perspective on the use of limited-dependent and qualitative variables models in accounting research, Accounting Review, 66, 788-807

Martín, J.C., Román, C. (2001) An application of DEA to measure the efficiency of Spanish airports prior to privatization, Journal of Air Transport Management, 7, 149157

Martín, J.C., Román, C. (2006) A Benchmarking Analysis of Spanish Commercial Airports. A Comparison between SMOP and DEA Ranking Methods, Network and Spatial Economics, 6, 111-134

McDonald, J. (2009) Using least squares and tobit in second stage DEA efficiency analyses, European Journal of Operational Research, 197, 792-798

Merkert, R., Assaf, A.G. (2015) Using DEA models to jointly estimate service quality perception and profitability- Evidence from international airports, Transportation Research Part A, 25, 42-50 
Merkert, R., Mangia, L. (2012) Management of airports in extreme winter conditionssome lessons for analyzing the efficiency of Norwegian airports, Research in Transportation Business \& Management, 4, 53-60

Merkert, R., Mangia, L. (2014) Explanatory power of different data envelopment analysis models for determining airports' cost-efficiency, Transportation Research Record: Journal of the Transportation Research Board, 13, 91-96

Merkert, R., Odeck, J., Brathen, S., Pagliari, R. (2012) A review of different benchmarking methods in the context of regional airports, Transport Reviews; 32, 379395

Pacheco, R.R., Fernandes, E., Santos, M.P.S. (2006) Management style and airport performance in Brazil, Journal of Air Transportation Management, 12, 324-330

Papke, L.E., Wooldridge, J.M. (1996) Econometric methods for fractional variables with an application to 401(k) plan participation rates, Journal of Applied Econometrics, $6,619-632$

Pathomsiri, S., Haghani, A., Dresner, M., Windle, R.J. (2008) Impact of undesirable outputs on the productivity of US airports, Transportation Research Part E, 44, 235259

Pels, E., Nijkamp, P., Rietveld, P. (2001) Relative efficiency of European airports, Transport Policy, 8, 183-192

Ramalho, E.A., Ramalho, J.J.S., Henriques, P.D. (2010) Fractional regression models for second stage DEA efficiency analyses, Journal of Productivity Analysis, 34, 239255

Ramalho, E.A., Ramalho, J.J.S., Murteira, J.M.R. (2011) Alternative estimating and testing empirical strategies for fractional regression models, Journal of Economic Surveys, 25, 1, 19-68

Ramalho, J. (2015) The frm Package. $R$ package Version 1.2.2, available at http://www.r-project.org 
Ruggiero, J. (1998) Non-discretionary inputs in data envelopment analysis, European Journal of Operational Research, 111, 461-469

Sarkis, J. (2000) An analysis of the operational efficiency of major airports in the United States, Journal of Operations Management, 18, 335-351

Sarkis, J., Talluri, S. (2004) Performance based clustering for benchmarking US airports, Transportation Research Part A, 38, 329-346

Sellner, R., Nagl, P. (2010) Air Accessibility and Growth - The Economic Effects of a Capacity Expansion at Vienna International Airport, Journal of Air Transport Management, 16, 325-329

Simar, L., Wilson, P. (2007) Estimation and inference in two-stage, semiparametric models of production processes, Journal of Econometrics, 136, 31-64

Steuer, R.E. (2006) ADBASE: A Multiple Objective Linear Programming Solver for Efficient Extreme Points and Unbounded Efficient Edges. Terry College of Business, University of Georgia, Athens, Georgia, USA

Steuer, R.E., Choo, E.U. (2003) An interactive weighted Tchebycheff procedure for multiple objective programming, Mathematical Programming, 26, 326-344

Suzuki, S., Nijkamp, P., Pels, E., Rietveld, P. (2014) Comparative performance analysis of European airports by means of extended data envelopment analysis, Journal of Advanced Transportation, 48, 185-202

Tsui, W.H.K., Balli, H.O., Gilbey, A., Gow, H. (2014) Operational efficiency of AsiaPacific airports, Journal of Air Transport Management, 40, 16-24

Wensveen, J.G. (2011) Air transportation: A managerial perspective, Airline Visions, Arlington, USA

Yu, M.M. (2004) Measuring physical efficiency of domestic airports in Taiwan with undesirable outputs and environmental factors, Journal of Air Transport Management, 10, 295-303 
Yu, M.M., Hsu, S.H., Chang, C.C., Lee, D.H. (2008) Productivity growth of Taiwan's major domestic airports in the presence of aircraft noise, Transportation Research Part $E, 44,543-554$

Zhang, B., Wu, H., Yang, X., Zhai, W., Xia, Q., Li, Y. (2014) An estimation of returns to scale of airports airsides under multiple optimal solutions in DEA, Journal of Air Transport Management, 40, 149-156 


\section{List of tables and figure captions}

Table 1. Literature survey of inputs/outputs in airport DEA models

Table 2. Data set for 21 European SMA (year 2013)

Table 3. Efficiency assessment results

Table 4. Benchmarks of technical inefficient airports

Table 5. Estimation results for linear, censored and fractional models (based on logit and cloglog functional forms)

Table 6. Partial effects for fractional regression models

Figure 1. Output increase estimation $\gamma_{0} \alpha_{\text {SCHROUT }}, \alpha_{\text {AIRLINES }}$ for each airport

Figure 2. Output Pareto efficient frontier corresponding to airport A6 
Table 1. Literature survey of inputs/outputs in airport DEA models

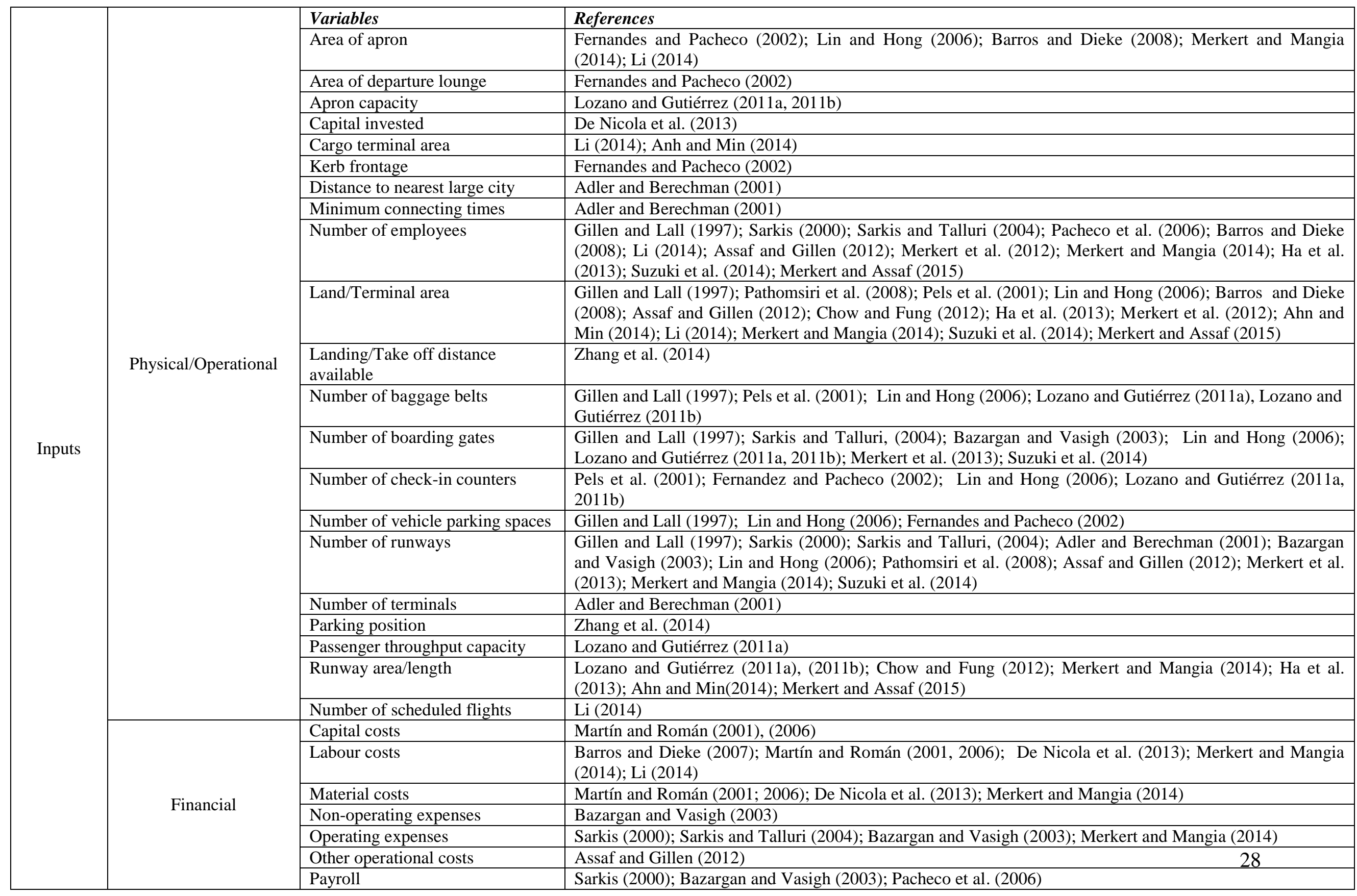


Table 1 (continued). Literature survey of inputs/outputs in airport DEA models

\begin{tabular}{|c|c|c|c|}
\hline \multirow{15}{*}{ Outputs } & \multirow{7}{*}{ Operational } & Aircraft Traffic Movements & $\begin{array}{l}\text { Sarkis (2000); Lin and Hong (2006); Lozano and Gutiérrez (2011a, 2011b); Assaf and Gillen (2012); } \\
\text { Merkert et al. (2012); De Nicola et al. (2013); Ahn and Min (2014), Merkert and Mangia (2014); Suzuki } \\
\text { et al. (2014); Merkert and Assaf (2015) }\end{array}$ \\
\hline & & Annual Passenger Movements & $\begin{array}{l}\text { Sarkis (2000); Lin and Hong (2006); Pathomsiri et al. (2008); Barros and Dieke (2008); Lozano and } \\
\text { Gutiérrez (2011a, (2011b); Assaf and Gillen (2012); Merkert et al. (2013); Merkert and Mangia (2014); } \\
\text { Ahn and Min (2014); Suzuki et al. (2014); Zhang et al. (2014); Merkert and Assaf (2015) }\end{array}$ \\
\hline & & Cargo handled & $\begin{array}{l}\text { Sarkis (2000); Sarkis and Talluri, (2004); Lin and Hong (2006); Barros and Dieke (2008); Pathomsiri et } \\
\text { al. (2008): Lozano and Gutiérrez (2011a, 2011b); Merkert et al. (2012); Merkert and Mangia (2014); Ahn } \\
\text { and Min (2014); Merkert and Assaf (2015) }\end{array}$ \\
\hline & & Commuter movements & Gillen and Lall (1997) \\
\hline & & $\begin{array}{l}\text { Overall passenger satisfaction/ } \\
\text { perceived service quality }\end{array}$ & Adler and Berechman (2001); De Nicola et al. (2013); Merkert and Assaf (2015) \\
\hline & & $\begin{array}{l}\text { Passenger and cargo (working load } \\
\text { unit) }\end{array}$ & Ha et al. (2013); De Nicola et al. (2013) \\
\hline & & Percentage of on time operations & Bazargan and Vasigh (2003); De Nicola et al. (2013) \\
\hline & \multirow{4}{*}{ Financial } & Commercial revenues & Pacheco et al. (2006) \\
\hline & & Non-aeronautical revenues & Assaf and Gillen (2012) \\
\hline & & Operating revenues & Sarkis (2000); Sarkis and Talluri, (2004); Pacheco et al. (2006) \\
\hline & & Operating margin (EBITDA) & Merkert and Assaf (2015) \\
\hline & \multirow{4}{*}{ Undesirable } & Accumulated flights delays & Pathomsiri et al. (2008); Lozano et al. (2013) \\
\hline & & Aircraft noise & Yu (2004); Yu et al. (2008) \\
\hline & & $\begin{array}{l}\text { Average conditional } \\
\text { delay of delayed flights }\end{array}$ & Lozano and Gutiérrez (2011b) \\
\hline & & $\begin{array}{l}\text { Number/Percentage of delayed } \\
\text { flights }\end{array}$ & Pathomsiri et al. (2008); Lozano and Gutiérrez (2011b) \\
\hline
\end{tabular}


Table 2. Dataset for 21 European SMA (year 2013)

\begin{tabular}{|c|c|c|c|c|c|c|c|c|c|c|c|c|c|}
\hline$\#$ & $\begin{array}{l}\text { IATA } \\
\text { code }\end{array}$ & Airport & Country & $\begin{array}{c}\text { RUNAREA } \\
\left(\mathbf{m}^{2}\right)\end{array}$ & $\begin{array}{c}\text { BOARDG } \\
\text { (\# gates) }\end{array}$ & $\begin{array}{c}\text { APRON } \\
\text { (\# stands) }\end{array}$ & $\begin{array}{c}\text { SCHEROUT } \\
\text { (\# routes) }\end{array}$ & $\begin{array}{c}\text { AIRLINES } \\
\text { (\# airlines) }\end{array}$ & $\begin{array}{c}\text { MOV } \\
\text { (\# mov.) }\end{array}$ & $\begin{array}{c}\text { PAX } \\
\text { (\# pax) }\end{array}$ & $\begin{array}{l}\text { CARGO } \\
\text { (Tonnes) }\end{array}$ & Ownership & Hub \\
\hline A1 & ANR & Antwerp & Belgium & 135,900 & 2 & 19 & 2 & 2 & 47,000 & 140,000 & 4,200 & Public & No \\
\hline $\mathrm{A} 2$ & BRN & Bern Belp & Switzerland & 51,900 & 5 & 12 & 35 & 3 & 56,000 & 240,000 & 0 & Private & Yes \\
\hline A3 & LNZ & Blue Danube & Austria & 180,000 & 12 & 16 & 35 & 15 & 10,900 & 624,000 & 43,000 & Public & No \\
\hline A4 & BUD & Budapest & Hungary & 302,265 & 38 & 44 & 86 & 37 & 83,830 & 852,100 & 92,112 & Private & Yes \\
\hline A5 & $\mathrm{CBG}$ & Cambridge Int'l & U.K. & 88,425 & 1 & 4 & 2 & 3 & 24,750 & 130,000 & 15 & Private & No \\
\hline A6 & CWL & Cardiff & U.K. & 110,032 & 15 & 17 & 18 & 9 & 24,879 & $1,072,062$ & 1,052 & Public & No \\
\hline A7 & GRQ & Groningen & Netherlands & 180,000 & 4 & 5 & 10 & 4 & 43,836 & 202,000 & 0 & Public & No \\
\hline A8 & INN & Innsbruck & Austria & 90,000 & 10 & 10 & 17 & 60 & 40,000 & $1,000,000$ & 3,000 & Public & No \\
\hline A9 & IOM & Isle of Man & U.K. & 194,120 & 6 & 13 & 10 & 5 & 31,833 & 746,817 & 2,034 & Public & No \\
\hline A10 & LCY & London City & U.K. & 35,970 & 14 & 18 & 47 & 10 & 120,000 & $3,003,000$ & 0 & Private & No \\
\hline A11 & SEN & London Southend & U.K. & 68,672 & 6 & 20 & 24 & 3 & 33,595 & $1,000,000$ & 16 & Public & No \\
\hline A12 & NTE & Nantes International & France & 130,500 & 22 & 27 & 63 & 18 & 48,000 & $3,631,693$ & 8,668 & Private & Yes \\
\hline A13 & NWI & Norwich & U.K. & 82,845 & 5 & 8 & 7 & 6 & 40,598 & 423,000 & 0 & Private & No \\
\hline A14 & PUY & Pula & Croatia & 132,570 & 5 & 10 & 29 & 32 & 7,300 & 377,428 & 11.5 & Private & No \\
\hline A15 & RJK & Rijeka & Croatia & 112,500 & 6 & 5 & 15 & 7 & 3,000 & 150,000 & 10 & Private & No \\
\hline A16 & RTM & Rotterdam The Hague & Netherlands & 101,700 & 8 & 19 & 24 & 8 & 53,899 & $1,500,000$ & 47 & Public & No \\
\hline A17 & SZG & Salzburg & Austria & 123,750 & 11 & 14 & 33 & 111 & 17,122 & $1,666,468$ & 8,127 & Private & No \\
\hline A18 & SNN & Shannon & Ireland & 144,000 & 13 & 17 & 22 & 8 & 24,264 & $1,400,032$ & 16,109 & Public & No \\
\hline A19 & SOU & Southampton & U.K. & 63,751 & 9 & 14 & 36 & 6 & 36,058 & $1,720,000$ & 0 & Private & Yes \\
\hline A 20 & FAE & Vagar & Faroe Islands & 37,500 & 2 & 5 & 9 & 1 & 5,268 & 225,532 & 611 & Public & Yes \\
\hline $\mathrm{A} 21$ & WAT & Waterford & Ireland & 32,959 & 2 & 4 & 1 & 1 & 9,000 & 30,000 & 0 & Public & No \\
\hline
\end{tabular}


Table 3. Efficiency assessment results

\begin{tabular}{|c|c|r|r|r|r|r|r|r|l|}
\hline Airport & $\gamma$ & $\mathrm{s}_{\text {MOV }}$ & $\mathrm{S}_{\text {PAX }}$ & $\mathrm{s}_{\text {CARGO }}$ & Eff $_{0}$ & Eff $_{0}^{\mathrm{CRS}}$ & Eff $_{0}^{\text {scale }}$ & Eff $_{0}^{\text {NIRS }}$ & RTS \\
\hline A1 & 1.000 & 0 & 0 & 0 & 1.000 & 1.000 & 1.000 & 1.000 & CRS \\
\hline A2 & 1.000 & 0 & 0 & 0 & 1.000 & 1.000 & 1.000 & 1.000 & CRS \\
\hline A3 & 1.000 & 0 & 0 & 0 & 1.000 & 1.000 & 1.000 & 1.000 & CRS \\
\hline A4 & 1.000 & 0 & 0 & 0 & 1.000 & 1.000 & 1.000 & 1.000 & CRS \\
\hline A5 & 1.000 & 0 & 0 & 0 & 1.000 & 1.000 & 1.000 & 1.000 & CRS \\
\hline A6 & 1.111 & 22,389 & 0 & 0 & 0.900 & 0.890 & 0.989 & 0.890 & IRS \\
\hline A7 & 1.000 & 0 & 0 & 0 & 1.000 & 1.000 & 1.000 & 1.000 & CRS \\
\hline A8 & 1.083 & 4,608 & 0 & 0 & 0.923 & 0.912 & 0.988 & 0.912 & IRS \\
\hline A9 & 1.000 & 0 & 0 & 0 & 1.000 & 1.000 & 1.000 & 1.000 & CRS \\
\hline A10 & 1.000 & 0 & 0 & 0 & 1.000 & 1.000 & 1.000 & 1.000 & CRS \\
\hline A11 & 1.000 & 0 & 0 & 0 & 1.000 & 1.000 & 1.000 & 1.000 & CRS \\
\hline A12 & 1.000 & 0 & 0 & 0 & 1.000 & 0.940 & 0.940 & 1.000 & DRS \\
\hline A13 & 1.000 & 0 & 0 & 0 & 1.000 & 1.000 & 1.000 & 1.000 & CRS \\
\hline A14 & 2.684 & 34,418 & 0 & 0 & 0.373 & 0.352 & 0.946 & 0.352 & IRS \\
\hline A15 & 2.232 & 24,838 & 0 & 0 & 0.448 & 0.180 & 0.403 & 0.180 & IRS \\
\hline A16 & 1.040 & 12,901 & 0 & 443 & 0.962 & 0.959 & 0.998 & 0.959 & IRS \\
\hline A17 & 1.070 & 55,109 & 0 & 0 & 0.934 & 0.907 & 0.971 & 0.907 & IRS \\
\hline A18 & 1.000 & 0 & 0 & 0 & 1.000 & 1.000 & 1.000 & 1.000 & CRS \\
\hline A19 & 1.042 & 31,863 & 0 & 204 & 0.960 & 0.943 & 0.983 & 0.943 & IRS \\
\hline A20 & 1.000 & 0 & 0 & 0 & 1.000 & 0.820 & 0.820 & 0.820 & IRS \\
\hline A21 & 1.000 & 0 & 0 & 0 & 1.000 & 0.738 & 0.738 & 0.738 & IRS \\
\hline
\end{tabular}


Table 4. Benchmarks of technically inefficient airports

\begin{tabular}{|c|c|}
\hline Inefficient airport & \multicolumn{1}{|c|}{ Benchmarks } \\
\hline A6 & A9 $(0.4635)$, A10 $(0.2725)$, A18 $(0.0141)$, A21 $(0.2500)$ \\
\hline A8 & A3 $(0.0019)$, A5 $(0.5571)$, A10 $(0.2447)$, A18 $(0.1962)$ \\
\hline A14 & A3 $(0.0005)$, A5 $(0.6922)$, A10 $(0.3073)$ \\
\hline A15 & A3 $(0.0002)$, A5 $(0.9285)$, A10 $(0.0713)$ \\
\hline A16 & A5 $(0.3140)$, A9 $(0.2397)$, A10 $(0.4463)$ \\
\hline A17 & A3 $(0.2019)$, A5 $(0.2568)$, A10 $(0.5405)$, A18 $(0.0008)$ \\
\hline A19 & A10 (0.5229), A11 $(0.1468)$, A20 (0.3303) \\
\hline
\end{tabular}


Table 5. Estimation results for linear, censored and fractional models (based on logit and cloglog functional forms)

\begin{tabular}{|c|c|c|c|c|}
\hline \multirow[t]{2}{*}{ Variable } & \multirow{2}{*}{$\begin{array}{l}\text { Linear } \\
\text { regression } \\
\text { model }\end{array}$} & \multirow{2}{*}{$\begin{array}{c}\begin{array}{c}\text { Censored regression } \\
\text { model }\end{array} \\
\text { Two limit Tobit }\end{array}$} & \multicolumn{2}{|c|}{$\begin{array}{c}\text { Fractional regression } \\
\text { models }\end{array}$} \\
\hline & & & Logit & Cloglog \\
\hline Ownership & $\begin{array}{l}-0.1552 * \\
(0.0765) \\
\end{array}$ & $\begin{array}{l}-0.3260 * \\
(0.1820)\end{array}$ & $\begin{array}{c}-2.4826 * * * \\
{[0.8596]}\end{array}$ & $\begin{array}{c}-0.8927 * * \\
{[0.3664]}\end{array}$ \\
\hline Hub & $\begin{array}{c}0.1492 \\
(0.0896)\end{array}$ & $\begin{array}{c}0.3809 \\
(0.2415) \\
\end{array}$ & $\begin{array}{c}3.2769 * * * \\
{[1.0956]}\end{array}$ & $\begin{array}{c}1.0746 * * * \\
{[0.3879]}\end{array}$ \\
\hline Constant & $\begin{array}{c}0.9668 * * * \\
(0.0498)\end{array}$ & $\begin{array}{c}1.2193 * * * \\
(0.1432)\end{array}$ & $\begin{array}{c}3.8219 * * * \\
{[0.5367]}\end{array}$ & $\begin{array}{c}1.3454 * * * \\
{[0.1367]}\end{array}$ \\
\hline Log sigma & - & $\begin{array}{c}-1.1911 * * * \\
(0.2951)\end{array}$ & - & - \\
\hline $\mathrm{R}^{2}$ & 0.221 & - & 0.254 & 0.254 \\
\hline $\mathrm{R}^{2}$ adjusted & 0.134 & - & & \\
\hline $\begin{array}{l}\text { McFadden's } \\
\text { pseudo- } \mathrm{R}^{2}\end{array}$ & - & 0.202 & - & - \\
\hline F statistic & 2.556 & - & - & - \\
\hline $\begin{array}{l}\text { Percentage of } \\
\text { predictions } \\
\text { outside the } \\
{[0,1] \text { interval }}\end{array}$ & 0.05 & - & - & - \\
\hline $\begin{array}{c}\text { Log - } \\
\text { likelihood }\end{array}$ & 9.9153 & -8.1155 & - & - \\
\hline $\begin{array}{c}\text { Order } 2 \text { - } \\
\text { RESET test }\end{array}$ & 0.7584 & - & 0.414 & 0.833 \\
\hline
\end{tabular}

Note 1: No. of observations=21; Standard errors are in parentheses; OLS standard errors (Linear model); ML standard errors (Tobit model); Robust standard errors are in square brackets; Levels of statistical significance are represented as follows: p-value $<0.01(* * *)$; p-value $<0.05(* *)$; p-value $<0.10(*)$.

Note 2: An additional regression analysis has been refitted, excluding A10 (LCY) from the sample (because due to its size it may be considered an outlier) and the results keep the significance indications and the magnitude and direction of the coefficient variables. 
Table 6. Partial effects for fractional regression models

\begin{tabular}{|l|c|c|}
\hline Variable & Logit & Cloglog \\
\hline \multirow{2}{*}{ Ownership } & $-0.1462^{*}$ & $-0.1262^{*}$ \\
& $(0.0878)$ & $(0.0647)$ \\
\hline \multirow{2}{*}{ Hub } & $0.1929 *$ & $0.1519^{*} *$ \\
& $(0.1113)$ & $(0.0723)$ \\
\hline
\end{tabular}

Note: p-value $<0.05(* *) ;$-value $<0.10(*)$. 
Figure 1. Output increase estimation $\gamma_{0} \alpha_{\text {SCHROUT }}, \alpha_{\text {AIRLINES }}$ for each airport

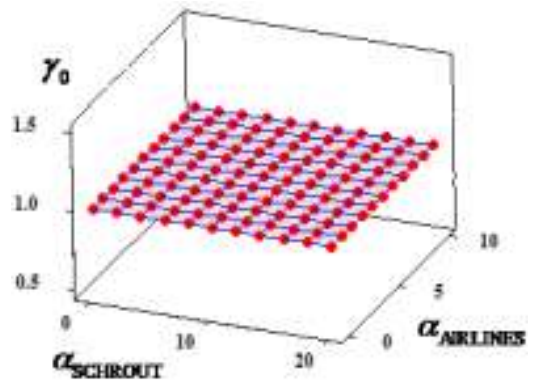

A1-A5, A7, A10, A12, A20, A21
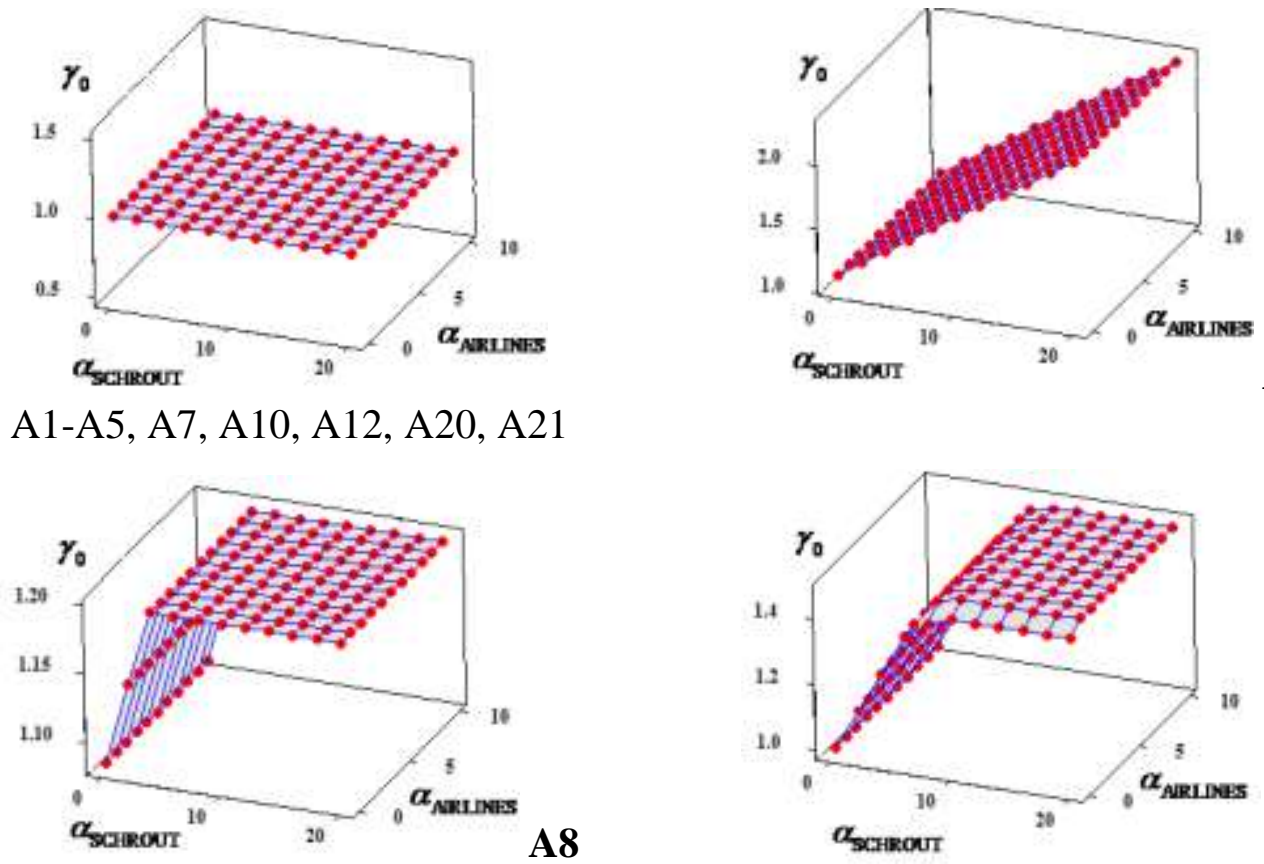

A6

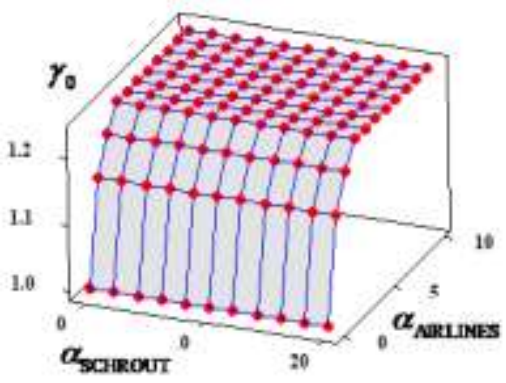

A11

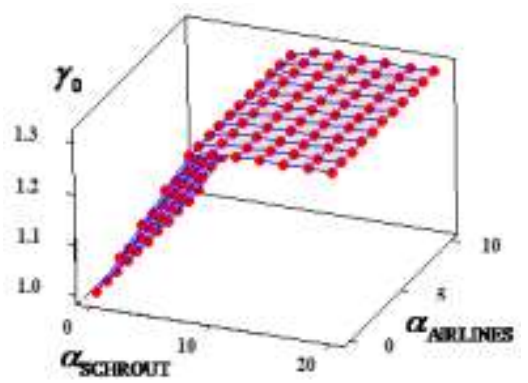

A9
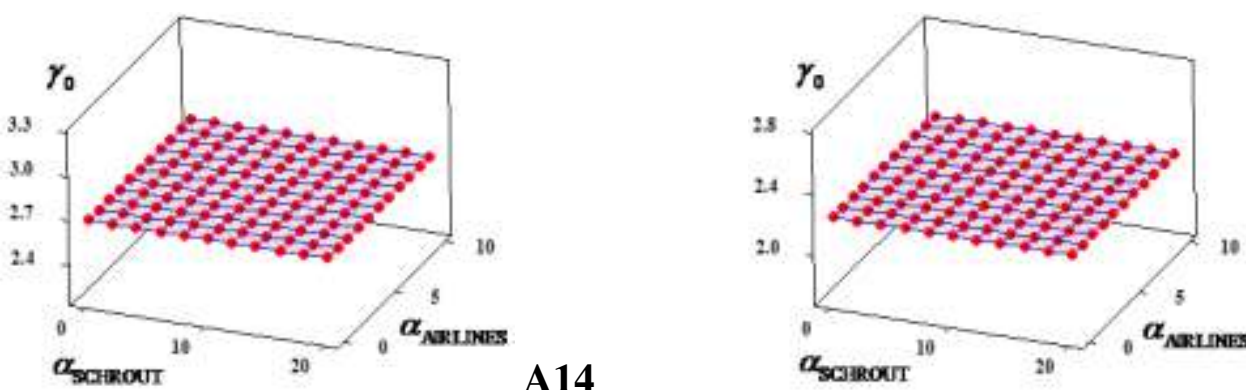

A13

A14

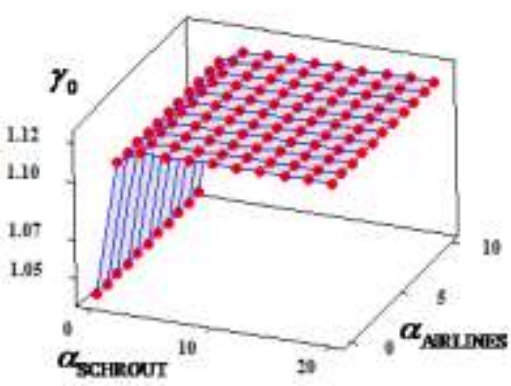

A16
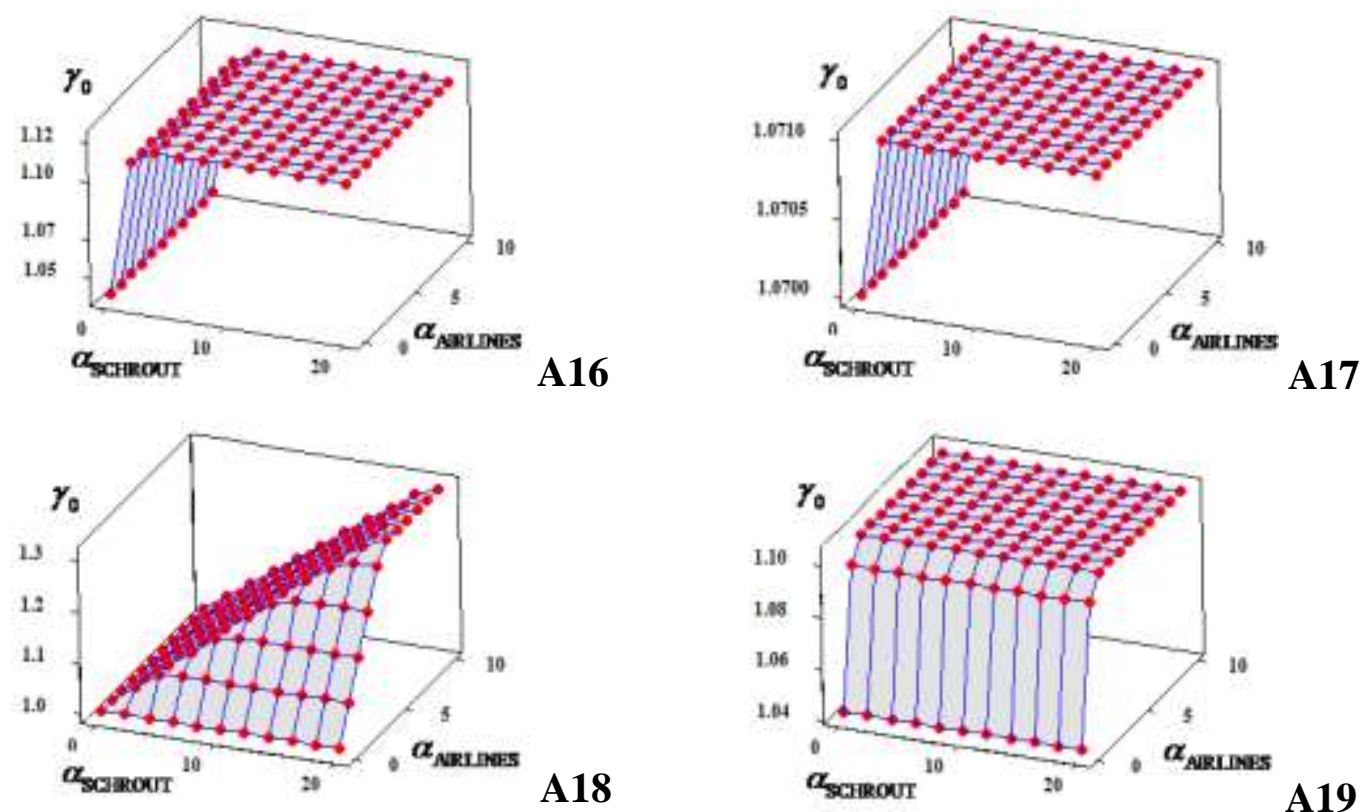
Figure 2. Output Pareto efficient frontier corresponding to airport A6
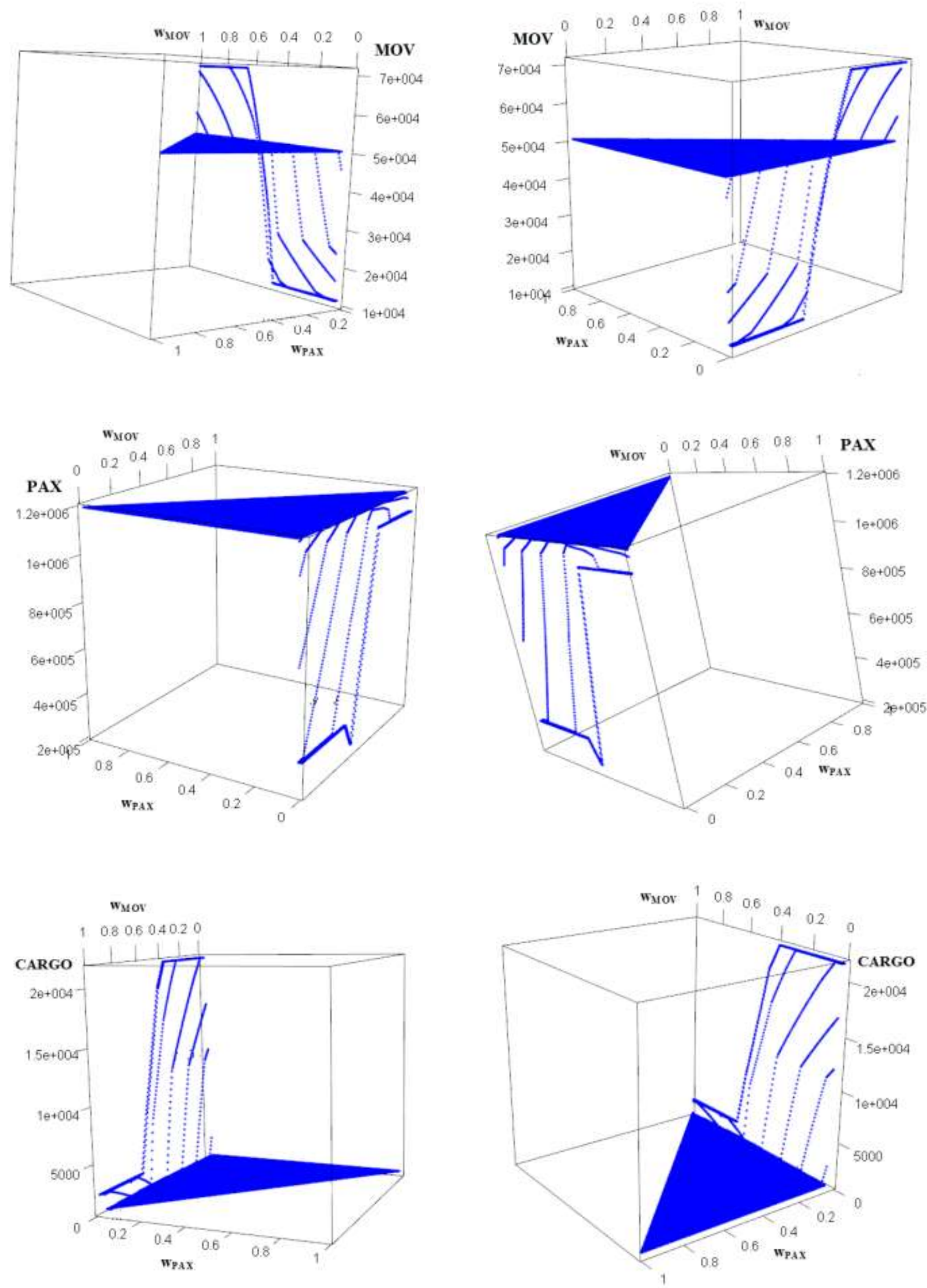